\title{
Towards a climate- dependent paradigm of ammonia emission and deposition
}

M.A. Sutton (NERC Centre for Ecology

\& Hydrology)

A. Bleeker (ECN) et al

April 2013

ECN-W--13-014 


\section{Author Queries}

Journal: Philosophical Transactions of the Royal Society B

Manuscript: rstb20130166

Q1 Please check the all the affiliations and the inserted city names, and amend if necessary.

Q2 Please provide volume and page range for ref. [63]. 
PHILOSOPHICAL TRANSACTIONS THE ROYAL
SOCIETY

\section{rstb.royalsocietypublishing.org}

\section{Research}

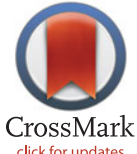

Cite this article: Sutton MA, Reis $S$, Riddick SN, Dragosits U, Nemitz E, Theobald MR, Tang YS, Braban CF, Vieno M, Dore AJ, Mitchell RF, Wanless S, Daunt F, Fowler D, Blackall TD, Milford C, Flechard CR, Loubet B, Massad R, Cellier P, Coheur PF, Clarisse L, van Damme M, Ngadi Y, Clerbaux C, Skjøth CA, Geels C, Hertel 0, Wichink Kruit RJ, Pinder RW, Bash J0, Walker JD, Simpson D, Horvath L, Misselbrook TH, Bleeker A, Dentener F, de Vries W. 2013 Towards a climate-dependent paradigm of ammonia emission and deposition. Phil Trans R Soc B 20130166. http://dx.doi.org/10.1098/rstb.2013.0166

One contribution of 15 to a Discussion Meeting Issue 'The global nitrogen cycle in the twentyfirst century'.

\section{Subject Areas:}

environmental science

\section{Keywords:}

ammonia, emission, deposition, atmospheric modelling

\section{Author for correspondence:}

Mark A. Sutton

e-mail: ms@ceh.ac.uk

Electronic supplementary material is available at http://dx.doi.org/10.1098/rstb.2013.0166 or via http://rstb.royalsocietypublishing.org.

\section{Towards a climate-dependent paradigm of ammonia emission and deposition}

Mark A. Sutton ${ }^{1}$, Stefan Reis ${ }^{1}$, Stuart N. Riddick',2, Ulrike Dragosits ${ }^{1}$, Eiko Nemitz ${ }^{1}$, Mark R. Theobald ${ }^{1,3}$, Y. Sim Tang ${ }^{1}$, Christine F. Braban¹, Massimo Vieno ${ }^{1}$, Anthony J. Dore ${ }^{1}$, Robert F. Mitchell ${ }^{1}$, Sarah Wanless ${ }^{1}$, Francis Daunt ${ }^{1}$, David Fowler', Trevor D. Blackall², Celia Milford", Chris R. Flechard ${ }^{5}$, Benjamin Loubet 5 , Raia Massad ${ }^{5}$, Pierre Cellier ${ }^{5}$, Pierre F. Coheur ${ }^{6}$, Lieven Clarisse ${ }^{6}$, Martin van Damme ${ }^{6}$, Yasmine Ngadi ${ }^{6}$, Cathy Clerbaux ${ }^{7,6}$, Carsten Ambelas Skjøth ${ }^{8}$, Camilla Geels ${ }^{8}$, Ole Hertel ${ }^{8}$, Roy J. Wichink Kruit ${ }^{9}$, Robert W. Pinder ${ }^{10}$, Jesse 0. Bash ${ }^{10}$, John D. Walker ${ }^{10}$, Dave Simpson ${ }^{11}$, Laszlo Horvath ${ }^{12}$, Tom H. Misselbrook ${ }^{13}$, Albert Bleeker ${ }^{14}$, Frank Dentener ${ }^{15}$ and Wim de Vries ${ }^{16}$

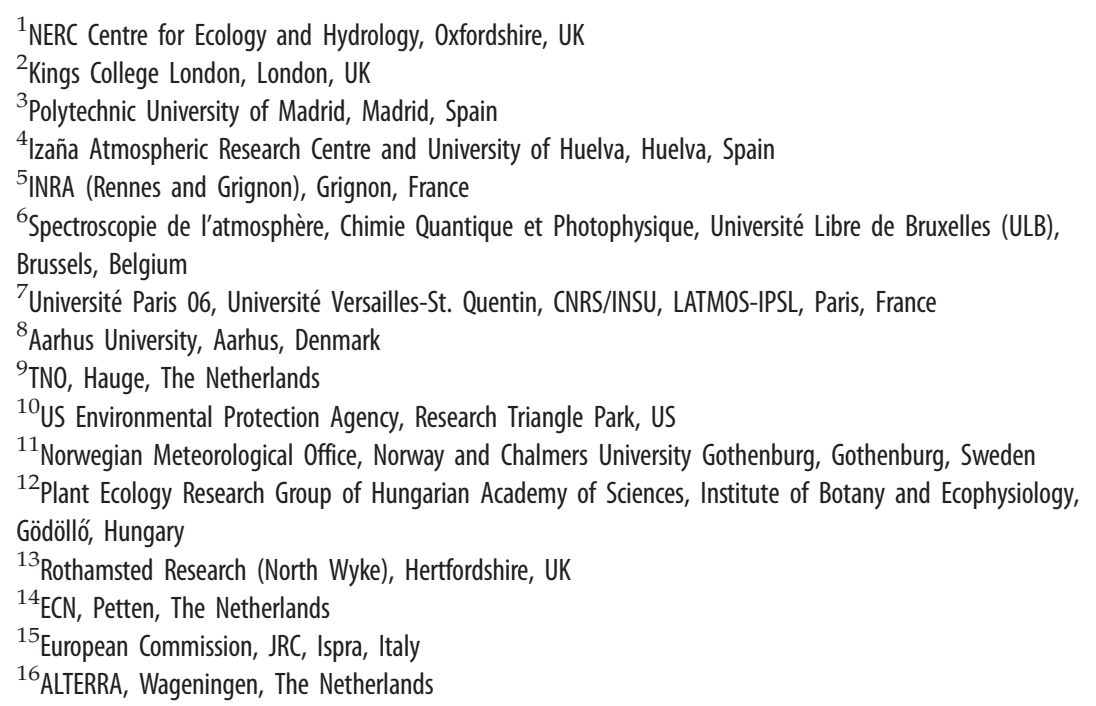

Existing descriptions of bi-directional ammonia $\left(\mathrm{NH}_{3}\right)$ land-atmosphere exchange incorporate temperature and moisture controls, and are beginning to be used in regional chemical transport models. However, such models have typically applied simpler emission factors to upscale the main $\mathrm{NH}_{3}$ emission terms. While this approach has successfully simulated the main spatial patterns on local to global scales, it fails to address the environment and climate-dependence of emissions. To handle these issues, we outline the basis for a new modelling paradigm where both $\mathrm{NH}_{3}$ emissions and deposition are calculated online according to diurnal, seasonal and spatial differences in meteorology. We show how measurements reveal a strong, but complex pattern of climatic dependence, which is increasingly being characterized using ground-based $\mathrm{NH}_{3}$ monitoring and satellite observations, whereas advances in process-based modelling are illustrated for agricultural and natural sources, including a global application for seabird colonies. A future architecture for $\mathrm{NH}_{3}$ emission-deposition modelling is proposed that integrates the spatio-temporal interactions, and provides the necessary foundation to assess the consequences of climate change. Based on available measurements, a first empirical estimate suggests that $5{ }^{\circ} \mathrm{C}$ warming would increase emissions by 42 per cent (28-67\%). Together with increased anthropogenic activity, global $\mathrm{NH}_{3}$ emissions may increase from 65 (45-85) $\mathrm{Tg} \mathrm{N}$ in 2008 to reach $132(89-179) \mathrm{Tg}$ by 2100. 
(a)

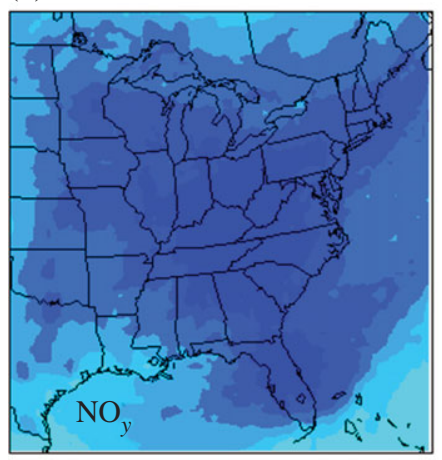

(b)

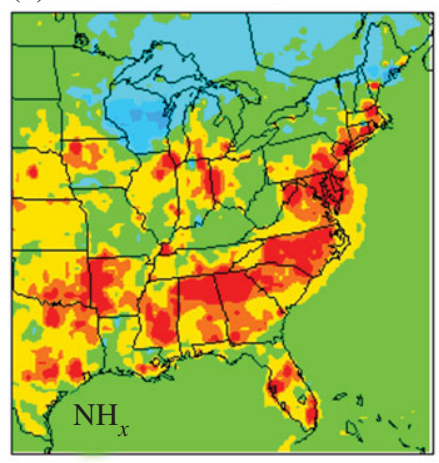

(c)

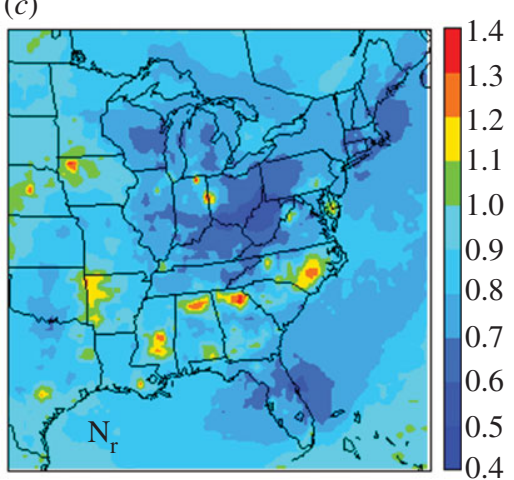

Figure 1. Simulated changes in N deposition in eastern USA, showing the ratios for 2020/2001 (adapted from Pinder et al. [5]). (a) 0xidized N deposition, (b) reduced $\mathrm{N}$ deposition and (c) total $\mathrm{N}$ deposition.

\section{Introduction}

Ammonia $\left(\mathrm{NH}_{3}\right)$ can be considered as representing the primary form of reactive nitrogen $\left(\mathrm{N}_{\mathrm{r}}\right)$ input to the environment. In the human endeavour to produce $\mathrm{N}_{\mathrm{r}}$ for fertilizers, munitions and other products, $\mathrm{NH}_{3}$ is the key manufactured compound, produced through the Haber-Bosch process [1]. Synthesis of $\mathrm{NH}_{3}$ is also the central step in the biological fixation of $\mathrm{N}_{2}$ to produce organic reduced nitrogen compounds $\left(\mathrm{R}-\mathrm{NH}_{2}\right)$, such as amino acids and proteins. When it comes to the decomposition of these organic compounds, ammonia and ammonium $\left(\mathrm{NH}_{4}^{+}\right)$, collectively $\mathrm{NH}_{x}$, are again among the first compounds produced. These changes lead to a cascade of transformations into different $\mathrm{N}_{\mathrm{r}}$ forms, with multiple effects on water, air, soil quality, climate and biodiversity, until $\mathrm{N}_{\mathrm{r}}$ is eventually denitrified back to $\mathrm{N}_{2}$.

Although the behaviour of ammonia has been of long interest at both micro- and macro-scales [2], recent scientific efforts and policies have given it much less attention than other $\mathrm{N}_{\mathrm{r}}$ forms. For example, under revision of the UNECE Gothenburg Protocol in 2012, the controls for $\mathrm{NH}_{3}$ were the least ambitious of all pollutants considered, with a projected decrease in $\mathrm{NH}_{3}$ emission for the EU (between 2010 and 2020) of only 2 per cent, compared with reductions of 30 per cent for $\mathrm{SO}_{2}$ and 29 per cent for $\mathrm{NO}_{x}$ (based on CEIP [3] and UNECE [4]).

In North America, India and China the expected trends are even more challenging. Figure 1 shows the relative changes in atmospheric $\mathrm{N}_{\mathrm{r}}$ deposition across the east of North America projected for 2001-2020 [5]. Despite increases in traffic volume, the implementation of technical measures to reduce $\mathrm{NO}_{x}$ emission from vehicles contributes approximately 40 per cent reduction in oxidized nitrogen $\left(\mathrm{NO}_{y}\right)$ deposition. By comparison, the minimal adoption of technical measures to reduce $\mathrm{NH}_{3}$ emission from agriculture is being offset by increased meat and dairy consumption, requiring more livestock and fertilizers, increasing $\mathrm{NH}_{x}$ deposition in some areas by less than 40 per cent.

The combination of weak international commitments to mitigate $\mathrm{NH}_{3}$ and increasing per capita consumption represents one of greatest challenges for future management of the nitrogen cycle [6,7]. The reality is that, rather than needing more $N_{r}$ to sustain 'food security', in developed parts of the world high levels of $\mathrm{N}_{\mathrm{r}}$ consumption are being used to sustain 'food luxurity' - the security of our food luxury. Ammonia must be a key part of the societal debate on these issues, where scientific advances in understanding and quantification are essential, especially as $\mathrm{NH}_{3}$ emission is one of the largest $\mathrm{N}_{\mathrm{r}}$ losses.
Most $\mathrm{NH}_{3}$ emissions result from agricultural production, and are strongly influenced by climatic interactions. In principle, according to solubility and dissociation thermodynamics, $\mathrm{NH}_{3}$ volatilization potential nearly doubles every $5^{\circ} \mathrm{C}$, equivalent to a $Q_{10}$ (the relative increase over a range of $10^{\circ} \mathrm{C}$ ) of $3-4$. At the same time, $\mathrm{NH}_{3}$ emission is controlled by water availability, which allows $\mathrm{NH}_{x}$ to dissolve, be taken up by organisms and be released through decomposition. Considering these interactions, $\mathrm{NH}_{3}$ emission and deposition are expected to be extremely climate-sensitive. For example, will climate warming increase in $\mathrm{NH}_{3}$ emissions and its environmental effects, and to what extent will this hinder $\mathrm{NH}_{3}$ mitigation efforts?

While substantial advances have been made in process-level understanding of $\mathrm{NH}_{3}$ land-atmosphere exchange [8-14], these advances have not been fully up scaled at national, continental and global levels. Bi-directional models using the 'canopy compensation point' approach $[10,15]$ have only been included to a limited extent in a few chemistry and transport models (CTMs) [5,16-18].

In addition, CTMs are still largely based on precalculated emission inventories. Under this approach, activity statistics are combined with emission factors to estimate annual emissions, which are mapped and typically with relatively simple temporal disaggregation. The resulting fixed emission estimates are attractive to policy users in relation to reporting national emissions commitments. However, the approach fails to recognize that a warm-dry year would tend to give larger $\mathrm{NH}_{3}$ emissions than a cold-wet year. At the same time, it does not address the short-term interactions relevant for risk assessment of $\mathrm{NH}_{x}$ impacts $[5,19,20]$.

To address these issues, this paper examines the relationships between climatic drivers and ammonia exchange processes. We first consider the magnitude of global $\mathrm{NH}_{3}$ emissions. Following consideration of the process relationships controlling $\mathrm{NH}_{3}$ exchange, we show how studies of a natural $\mathrm{NH}_{3}$ source (seabird colonies) can be used to demonstrate the climatic dependence of emission and verify a global model. Finally, we outline a new architecture that sets the challenge for a new paradigm for regional modelling of atmospheric $\mathrm{NH}_{x}$ as the basis for incorporating the effects of climate differences and climate change.

\section{Ammonia emission inventories}

The main reasons for constructing $\mathrm{NH}_{3}$ emissions inventories have been to meet national-scale policy requirements and 
provide input to CTMs. Among the best studied national $\mathrm{NH}_{3}$ inventories are the Netherlands [21], Denmark [22]; UK [23,24], Europe [25] and the US [5].

Although there is frequently debate on the absolute magnitude of national emissions and their consistency with atmospheric measurements [26], such inventories have allowed high-resolution CTMs to show a close spatial correlation with annual atmospheric $\mathrm{NH}_{3}$ and $\mathrm{NH}_{4}^{+}$concentrations. In Europe, the inventories have focused especially on livestock housing and grazing, storage and spreading of manures, and from mineral fertilizers [27]. Less attention has been given to non-agricultural emissions including sewage, vehicles, pets, fish ponds, wild animals and combustion, which can contribute 15 per cent to national totals $[28,29]$.

By comparison with the best national estimates, global $\mathrm{NH}_{3}$ emission inventories are much less certain. This reflects the wider diversity of sources and fewer underpinning data, combined with a paucity of activity statistics (e.g. animal numbers, bodyweights, diets, etc.). The contrast is illustrated between Denmark, where $1 \mathrm{~km}$ resolution data on livestock numbers account for species sub-classes and abatement techniques [30], and other parts of the world, where such statistics often do not even exist.

Recent global estimates of annual $\mathrm{NH}_{3}$ emission are summarized in table 1. Dentener \& Crutzen [16] were the first to to derive a global $10^{\circ} \times 10^{\circ} \mathrm{NH}_{3}$ emission inventory for input to global CTMs. Bouwman et al. [31] made a global $\mathrm{NH}_{3}$ inventory for the main sources at $1^{\circ} \times 1^{\circ}$ for 1990 , whereas Beusen et al. [33] extended this for livestock and fertilizers.

One of the first points to note in the global comparison is that the source nomenclature is not well harmonized. Current standardization of inventory reporting by EDGAR [34] and the UNFCCC focuses strongly on combustion sources and is less suited for sector analysis of agricultural emissions. It is, therefore, not easy to distinguish the main livestock sectors in the most recent inventories. According to Dentener \& Crutzen [16], of $22 \mathrm{Tg} \mathrm{NH}_{3}-\mathrm{N} \mathrm{yr}^{-1}$ emitted from livestock, 65 per cent was from cattle and buffalo, with 13 per cent, 11 per cent, 6 per cent and 5 per cent, from pigs, sheep/ goats, poultry and horses/mules/asses, respectively.

The degree of agreement shown in table $1\left(35-54 \mathrm{Tg} \mathrm{N} \mathrm{yr}^{-1}\right)$ results partly from dependence on common datasets (e.g. FAO) and partly because of including different emission terms in each inventory. If all sources listed among the inventories are combined, this gives a total of 59 and $65 \mathrm{Tg} \mathrm{N} \mathrm{yr}^{-1}$ for 2000 and 2008 , respectively. These values are based on the recent estimates of EDGAR, combined with approximately $8 \mathrm{Tg} \mathrm{yr}^{-1}$ from oceans and approximately $12 \mathrm{Tg} \mathrm{yr}^{-1}$ from humans, waste, pets, wild animals and natural soils.

These estimates should be considered uncertain by at least $\pm 30 \%$ (based on propagation of likely ranges for input data, [33], indicating an emission range of $46-85 \mathrm{Tg} \mathrm{N}$ for 2008, although a formal uncertainty analysis on the full inventory has never been conducted. Apart from the uncertainties related to emission factors and climatic dependence, inaccurate activity data may introduce regional bias. For example, comparison of $\mathrm{NH}_{3}$ satellite observations (see \$4) with a global CTM showed substantial underestimation by the CTM in central Asia [37], suggesting an under-reporting of animal numbers and fertilizer use in these countries.

Figure 2 shows that the regions of the world with highest emissions are mostly associated with livestock and crops. Because the available sector categorization does not distinguish arable and livestock sectors, the brown shaded areas represent locations with a very strong livestock dominance. Biomass burning is the main $\mathrm{NH}_{3}$ source across much of central Africa, where estimated $\mathrm{NH}_{3}$ emissions reach levels similar to peak agricultural values of India and China. Inclusion of the recent estimates of Riddick et al. [35] shows how seabird colonies are a significant $\mathrm{NH}_{3}$ source for many subpolar locations. These global maps hide substantial local variability, as illustrated for the UK in the electronic supplementary material, figure S1.

It must be emphasized, however, that these global estimates only take climate factors into account in a limited way. For emissions from fertilizer and manure application, climate has been partly considered by grouping datasets into major temperature regions [38], whereas Riddick et al. [35] applied a simple temperature function. However, the published global inventories do not model $\mathrm{NH}_{3}$ at a process-level in relation to changing meteorological conditions. In addition, bi-directional $\mathrm{NH}_{3}$ fluxes from crops, sparsely grazed land and natural vegetation provide a particular challenge, because both the magnitude and direction of the flux varies according to ecosystem, management and environmental variables.

\section{Concepts for modelling ammonia land- atmosphere exchange}

Current conceptual frameworks on $\mathrm{NH}_{3}$ exchange show how fluxes respond to short-term variation in environmental conditions, and hence to long-term climate differences. This can be illustrated by the case of bi-directional exchange between plant, soil and atmosphere.

Ammonia fluxes are often considered as representing a potential difference between two gas-phase concentrations constrained by a set of resistances. At its simplest, the concentration at the surface $\chi\left(z_{\mathrm{o}^{\prime}}\right)$, where $z_{\mathrm{o}^{\prime}}$ is the notional height of $\mathrm{NH}_{3}$ exchange, is contrasted with the concentration $\chi(z)$ at a reference height $z$ above the canopy, with the total flux $\left(F_{\mathrm{t}}\right)$ :

$F_{\mathrm{t}}=\frac{\left[\chi\left(z_{\mathrm{o}^{\prime}}\right)-\chi(z)\right]}{\left[R_{\mathrm{a}}(z)+R_{\mathrm{b}}\right]}$,

where $R_{\mathrm{a}}(z)$ and $R_{\mathrm{b}}$ are the turbulent atmospheric and quasilaminar boundary layer resistances, respectively $[10,15]$. A well-known variant of this approach, applicable only for deposition, assumes that the concentration at the absorbing surface is zero, so that any limitation to uptake can be assigned to a canopy resistance $\left(R_{\mathrm{c}}\right)$ :

$F_{\mathrm{t}}=\frac{[0-\chi(z)]}{\left[R_{\mathrm{a}}(z)+R_{\mathrm{b}}+R_{\mathrm{c}}\right]}$,

where an associated term, the deposition velocity, is defined as $V_{\mathrm{d}}(z)=\left(R_{\mathrm{a}}(z)+R_{\mathrm{b}}+R_{\mathrm{c}}\right)^{-1}=-F_{\mathrm{t}} / \chi(z)$. It is possible to interpret $\mathrm{NH}_{3}$ flux measurements according to either view. This is illustrated in the electronic supplementary material, figure S2, which summarizes results from a year of continuous hourly $\mathrm{NH}_{3}$ flux measurements over an upland moorland in Scotland [39]. Applying equation (3.1) to the flux measurements demonstrates the relationship between $\chi\left(z_{\mathrm{o}^{\prime}}\right)$ and canopy temperature, while applying equation (3.2) to calculate $R_{\mathrm{c}}$ for the same dataset is necessarily restricted to periods where deposition was recorded. These two approaches represent different views of the factors driving and constraining the net flux. 
Table 1. Comparison of global ammonia emission estimates $\left(\operatorname{Tg~N~yr}^{-1}\right)$.

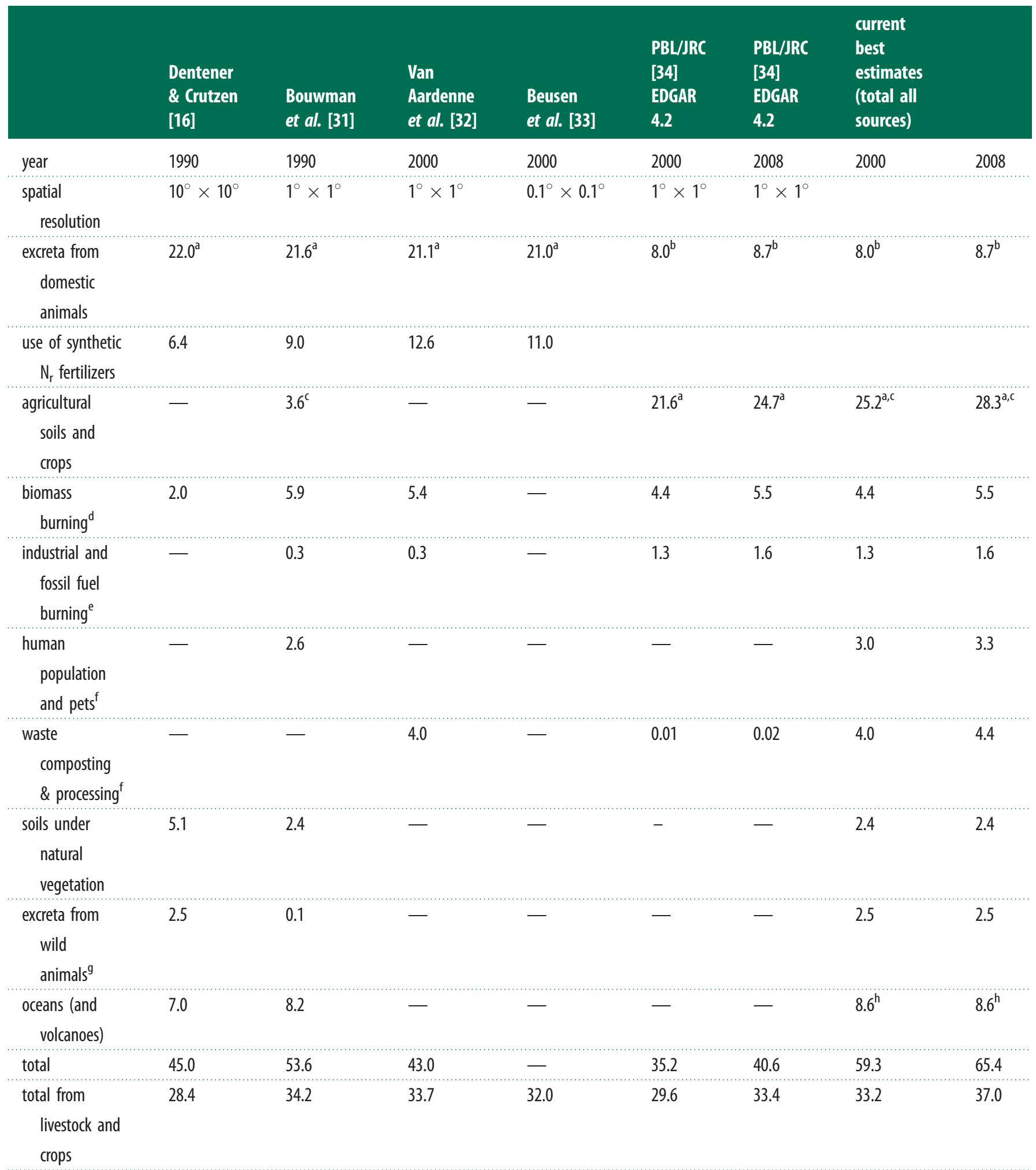

ancludes emissions from grazing and land application of animal manure.

${ }^{b}$ Excludes emissions from land application of animal manure.

Includes estimated direct crop emissions from foliage and leaf litter.

'Including savannah, agricultural waste, forest, grassland and peatland burning/fires.

${ }^{e}$ Not including potentially high emissions from low-efficiency domestic coal burning [2].

fRescaled by global population increase.

${ }^{9}$ The estimate of Bouwman et al. [31] is considered low given $\mathrm{NH}_{3}$ emissions from seabird colonies alone of $0.2 \mathrm{Tg} \mathrm{N} \mathrm{yr}^{-1}$ [35].

hincludes an upper estimate of $0.4 \mathrm{Tg} \mathrm{N} \mathrm{yr}^{-1}$ as $\mathrm{NH}_{x}$ from volcanoes based on an emission ratio of $15 \% \mathrm{NH}_{x}$ : $\mathrm{SO}_{2}$ [2] and volcanic $\mathrm{SO}_{2}$ emissions of $6.7 \mathrm{Tg} \mathrm{S} \mathrm{yr}^{-1}[36]$. 


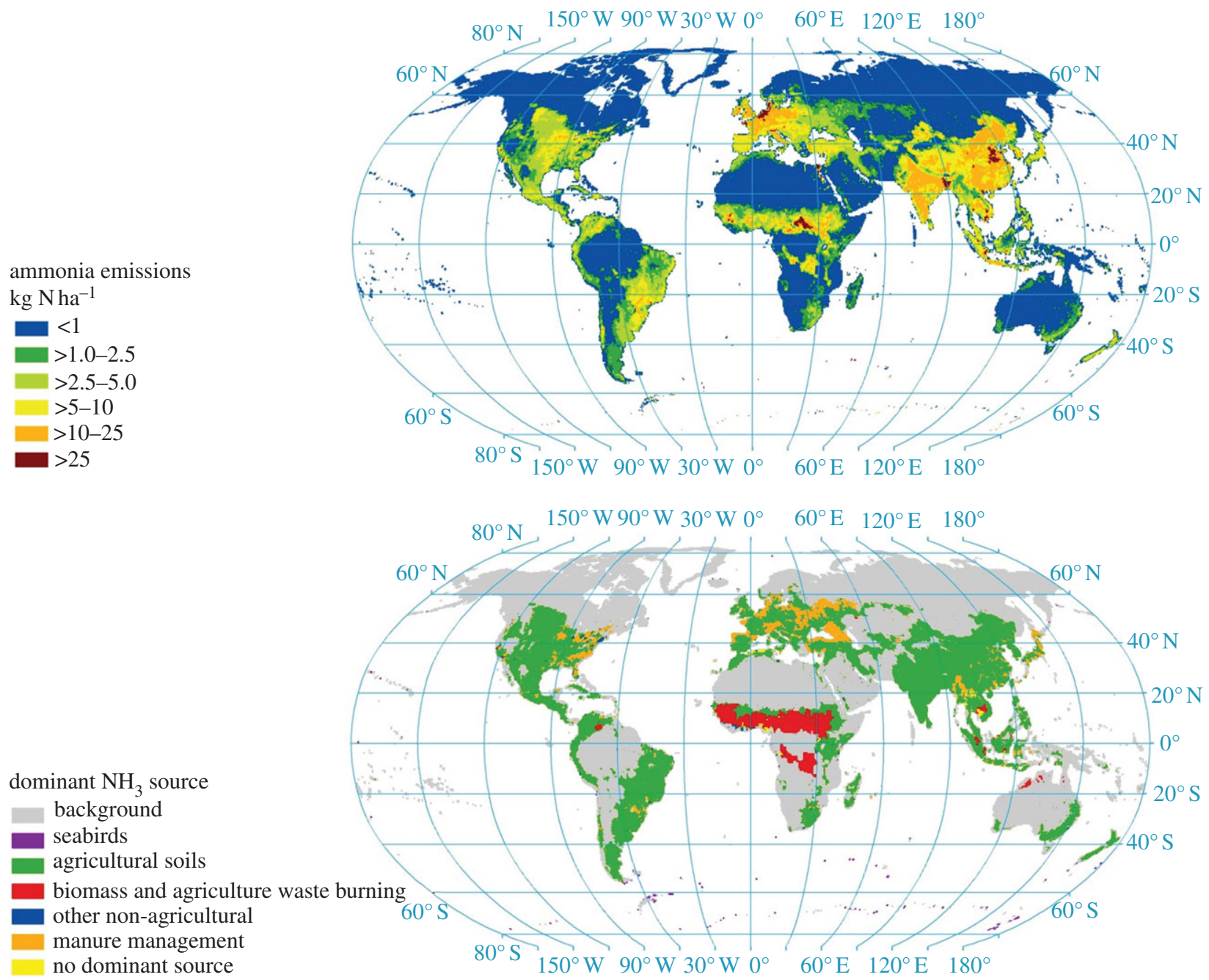

Figure 2. Spatial variability in global ammonia emissions based on JRC/PBL [34] (livestock, fertilizers, biomass burning, fuel consumption) and Riddick et al. [35] (seabirds). Emissions from oceans, humans, pets, natural soils and other wild animals (table 1) are not mapped. High-resolution maps for the UK are given in the electronic supplementary material, figure $\mathbf{S 1}$.

The value of $\chi\left(z_{\mathrm{o}^{\prime}}\right)$ at the surface is proportional to a ratio termed $\Gamma=\left[\mathrm{NH}_{4}^{+}\right] /\left[\mathrm{H}^{+}\right]$, where according to the thermodynamics:

$\chi=\frac{161500}{T \exp ^{(-10380 / T)}\left[\mathrm{NH}_{4}^{+}\right] /\left[\mathrm{H}^{+}\right]}$,

with $T$ in Kelvin [15]. The existence of bi-directional fluxes illustrated in the electronic supplementary material, figure S2 shows that calculating $\chi\left(z_{\mathrm{O}^{\prime}}\right)$ provides the more general solution, whereas its increase according to thermodynamics (fitted line, $Q_{10}=3-4$ ) suggests that it reflects a process reality. An exception is seen in frozen conditions, where $R_{\mathrm{c}}$ may be better suited to describe slow rates of deposition, as seen also for other gases [40]. However, considering the full year of measurements, the clear relationship with $\chi\left(z_{\mathrm{o}^{\prime}}\right)$ in electronic supplementary material, figure S2 illustrates the weakness of sole reliance on the $R_{\mathrm{c}}$ and $V_{\mathrm{d}}$ approach typically applied in CTMs.

The approach described above outlines the most simple situation. In reality, each of surface concentrations, resistances and even capacitances can be used to simulate $\mathrm{NH}_{3}$ exchange, whereas both advection and gas-particle interactions can also affect fluxes [11,41,42]. A framework to consider the key issues at the plot scale is shown in figure 3, largely based on Sutton et al. [10,43], Flechard et al. [44] and Nemitz et al. [15]. In this development of the resistance analogy, the central term is the 'canopy compensation point' $\left(\chi_{\mathrm{c}}\right)$, which is identical to $\chi\left(z_{\mathrm{o}^{\prime}}\right)$ when $F_{\mathrm{t}}=0$. This is contrasted with the 'stomatal compensation point' $\left(\chi_{\mathrm{s}}\right)$, which is the $\mathrm{NH}_{3}$ gas concentration at equilibrium with $\left[\mathrm{NH}_{4}^{+}\right] /\left[\mathrm{H}^{+}\right]$in the apoplast, $\Gamma_{\text {apo. }}$. Available data suggest only modest diurnal variation in $\Gamma_{\text {apo }}$ [11]. The main challenge, therefore, is to estimate the larger differences in $\Gamma_{\text {apo }}$ owing to management, plant species and seasonality [45-47]. This can be investigated by including $\mathrm{NH}_{3}$ cycling in models of ecosystem dynamics and agricultural management [11,18,48-50].

The most widely used approach to simulate $\mathrm{NH}_{3}$ exchange with the cuticle is to assume that deposition is constrained by a cuticular resistance $\left(R_{\mathrm{W}}\right)[10,15]$. General parametrizations of this response to humidity and to $\mathrm{NH}_{3}$ : acid-gas ratios have been developed ([15,46,51]; electronic supplementary material, figure S3; figure 3, scheme 1). These approaches have the advantage of relative simplicity, but only represent a steady-state approximation to a dynamic reality, where both adsorption (favouring net deposition) and desorption (favouring emission) occur in practice.

This dynamic view can be addressed by scheme 2 of figure 3 . In the simplest description, a time-constant can be set for charging and discharging the leaf-surface water/cuticular pool of $\mathrm{NH}_{x}$ (e.g. $R_{\mathrm{d}}=5000 / C_{\mathrm{d}}, \mathrm{s} \mathrm{m}^{-1}$ ), combined with a fixed leaf-surface $\mathrm{pH}$ [43]. A more sophisticated approach solves the ion balance of the leaf-surface water, calculating 


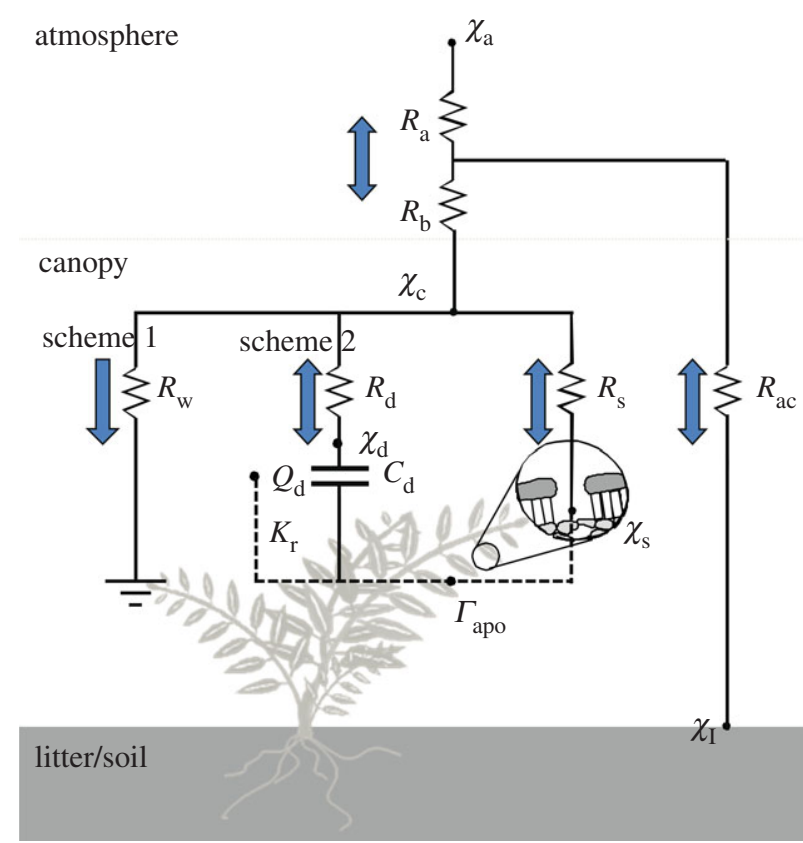

Figure 3. Resistance analogue of $\mathrm{NH}_{3}$ exchange including cuticular, stomatal and ground pathways. Two schemes for cuticular exchange are illustrated: scheme 1, steady-state uptake according to a varying cuticular resistance $\left(R_{\mathrm{w}}\right)$; scheme 2, dynamic exchange with a pool of $\mathrm{NH}_{4}^{+}$treated with varying capacitance $\left(C_{d}\right)$ and charge $\left(Q_{d}\right)$. Other resistances are for turbulent atmospheric transfer $\left(R_{\mathrm{a}}\right)$, the quasi-laminar boundary layer $\left(R_{\mathrm{b}}\right)$, within-canopy transfer $\left(R_{\mathrm{ac}}\right)$, cuticular adsorption/desorption $\left(R_{\mathrm{d}}\right)$ and stomatal exchange $\left(R_{\mathrm{s}}\right)$. Also shown are the air concentration $\left(\chi_{\mathrm{a}}\right)$, cuticular concentration $\left(\chi_{\mathrm{d}}\right)$, stomatal compensation point $\left(\chi_{\mathrm{s}}\right)$, litter/soil surface concentration $\left(\chi_{1}\right)$ and the canopy compensation point $\left(\chi_{c}\right)$. Exchange between aqueous $\mathrm{NH}_{4}^{+}$pools is shown with dashed lines, including $K_{\mathrm{r}}$, the exchange rate between leaf surface and apoplast.

cuticular $\mathrm{pH}$ according to the concentrations, fluxes and precipitation inputs of all relevant compounds [44,52]. In an extended application to measurements over forest, Neirynck \& Ceulemans [53] tested the simpler application of scheme 2, finding it to simulate duirnal to seasonal measured fluxes much more closely than scheme 1 . One of the main uncertainties in applying scheme 2 is the exchange of aqueous $\mathrm{NH}_{4}^{+}$and other ions between leaf surface and apoplast.

The last component of figure 3 describes $\mathrm{NH}_{3}$ exchange with the ground surface. Although flux measurements have often shown significant emission from soils and especially with leaf litter $[8,11,15]$, this term remains the most uncertain. In particular, the extent to which soil $\mathrm{pH}$ influences $\mathrm{pH}$ at atmospheric exchange surfaces such as leaf litter and in the vicinity of applied fertilizer and manure remains poorly quantified, while the liberation of $\mathrm{NH}_{3}$ from organic decomposition directly influences local substrate $\mathrm{pH}$. Further measurements are needed to develop simple parametrizations of $\Gamma_{1}$ for litter and to inform the development of ecosystem models simulating $\Gamma_{1}$ in relation to litter quality, water availability, mineralization, immobilization and nitrification rates.

Similar interactions apply to other $\mathrm{NH}_{3}$ volatilization sources. For example, the VOLT'AIR model provides a process simulation of $\mathrm{NH}_{3}$ emissions from the land application of liquid manures [54,55], where manure placement method and calculated soil infiltration rates inform the calculation of $\chi\left(z_{0^{\prime}}\right)$. Empirical approaches have also been used to parametrize $\mathrm{NH}_{3}$ emissions directly from manure application, using regression with experimental studies [56]. Such empirical relationships have also been applied to estimate $\mathrm{NH}_{3}$ emissions from animal houses, manure stores and manure spreading (see the electronic supplementary material, section S3). It remains a future challenge to develop process models for these sources based on the principles of equation (3.1).

\section{Quantifying environmental relationships with ammonia fluxes and concentrations}

From the preceding examples it can be seen that temperature and moisture play a key role in determining the concentration of $\mathrm{NH}_{3}$ in equilibrium with surface pools and hence in defining net $\mathrm{NH}_{3}$ fluxes on diurnal to annual scales. However, the interaction between these and other factors (e.g. stomatal opening, growth dilution of $\mathrm{NH}_{x}$ pools, soil infiltration and decomposition rates) means that the temperature-dependence of $\mathrm{NH}_{3}$ emission may not always follow the thermodynamic response.

These interactions are illustrated in the electronic supplementary material, figure S3b, which shows the values of $\chi_{\mathrm{c}}$ for periods when the net flux was zero, from $\mathrm{NH}_{3}$ flux measurements over dry heathland [57]. Under very dry conditions (relative humidity, $h<50 \%$ ), cuticular fluxes appear to have been small, so that $\chi_{\mathrm{c}} \sim \chi_{\mathrm{s}}$, with a clear temperature*dependence in the range $Q_{10}$ of $2-4$. By contrast, at $h$ in the range $50-70 \%$, there was less relationship to temperature, pointing to a significant role of cuticular adsorption/ desorption processes.

The way in which plant growth interactions may alter the temperature response of $\mathrm{NH}_{3}$ fluxes can be illustrated by the process model PaSim. Based on its application to measured fluxes over Scottish grassland [48], the model was used to consider scenarios of altered annual air temperature, keeping all other factors the same as the original simulation. The effect of cutting and fertilization on the net $\mathrm{NH}_{3}$ flux and illustrative $\mathrm{N}_{\mathrm{r}}$ pools are shown in figure 4 . PaSim included the standard thermodynamic dependence of both $\chi_{\mathrm{s}}$ and $\chi_{\text {soil }}$ equation (3.3) to simulated values of $\Gamma_{\mathrm{s}}$ and $\Gamma_{\text {soil }}$ (combined with scheme 1 using $\left.R_{\mathrm{w}}=30 \mathrm{e}^{(100-h) / 7} \mathrm{~s} \mathrm{~m}^{-1}\right)$. It is, therefore, notable that the net flux showed only a modest temperaturedependence, with the net flux for the month increasing with $Q_{10}=1.5$. Only immediately after fertilizer application did the flux increase with $Q_{10}=3.2$. This can be explained by the warmer temperatures leading to more rapid grass growth, decreasing leaf substrate $\mathrm{N}_{\mathrm{r}}$ and modelled $\Gamma_{\mathrm{s}}$ (figure 4). Although further measurements have also shown a role of leaf litter processes not currently treated in PaSim [11], the simulation demonstrates how growth-related factors can offset the simple thermodynamic $\mathrm{NH}_{x}$ response.

A similar message emerges for $\mathrm{NH}_{3}$ emissions from landspreading of manures using the ALFAM multiple regression model [56], which includes a weak temperature response $\left(Q_{10}=1.25\right)$. This broadly agrees with a simple empirical approach for pig slurry for the UK ammonia inventory [27], though, for cattle slurry, the distinction between summer and other months in the inventory equates to $Q_{10}=2.5$. In this case, the key interaction appears to be between volatilization potential and slurry infiltration rate, which can be limited in both waterlogged and hard-dry soils.

Atmospheric $\mathrm{NH}_{3}$ monitoring can also inform the simulation of seasonal dynamics. In the case of the UK and Danish ammonia networks, areas dominated by cattle and pig show 


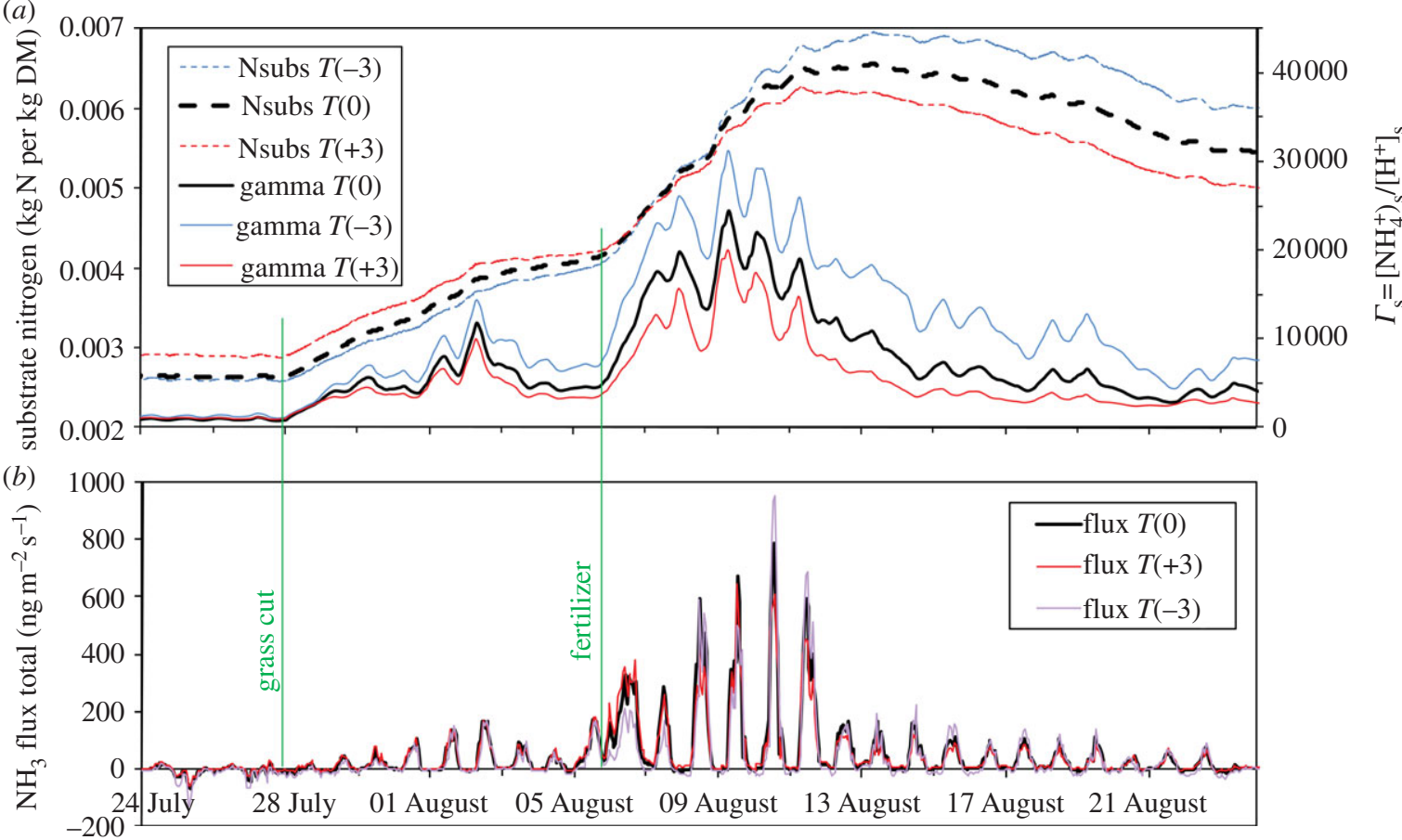

Figure 4. Effect of temperature scenarios (annual change of $+3^{\circ} \mathrm{C}$ and $-3^{\circ} \mathrm{C}$ ) on $(a)$ simulated nitrogen pools (foliar substrate $\mathrm{N}$, and $\Gamma_{\mathrm{s}}$ ) and $(b)$ net $\mathrm{NH}_{3}$ fluxes. Simulations conducted using the PaSim model for managed grassland in Scotland following cutting and fertilization with ammonium nitrate.

peak emissions in spring, which are reproduced by models accounting for the timing of manure spreading [30,58]. However, the UK also includes substantial background areas (see the electronic supplementary material, figure S1) with a pronounced summer maximum and winter minimum of 0.43 and $0.04 \mu \mathrm{g} \mathrm{NH}_{3} \mathrm{~m}^{-3}$, respectively, while sheep dominated upland areas show a similar annual cycle (0.95 and $0.17 \mu \mathrm{g} \mathrm{m}^{-3}$, respectively). These seasonal patterns are not reproduced in CTMs as they do not adequately treat the climatic dependence of grazing emissions [58]. As the grazing animals that dominate emissions in these areas are outdoors all year, a $12^{\circ} \mathrm{C}$ difference between the mean temperature of warmest and coolest month equates to $Q_{10}$ of 9.0 and 4.7 for background and sheep sites, respectively. These large values suggest that other factors enhance the temperature-dependence of $\mathrm{NH}_{3}$ concentrations, with more rapid scavenging in winter.

Such seasonal differences can also be seen from globally monitored satellite columns of $\mathrm{NH}_{3}$ at $12 \times 12 \mathrm{~km}^{2}$ resolution at nadir, through processing of retrievals from the infrared atmospheric sounding interferometer on the MetOp platform. This approach is based on the absorption spectra of $\mathrm{NH}_{3}$ in the infrared and depends on a strong thermal contrast between the ground and atmosphere, measuring $\mathrm{NH}_{3}$ columns that are dominated by high concentrations in the lowest $1-2 \mathrm{~km}$ [37]. Retrievals are made twice a day, allowing extensive comparison with environmental and seasonal $\mathrm{NH}_{3}$ dynamics.

An illustration of the satellite retrieval is shown in figure 5, which compares the mean $\mathrm{NH}_{3}$ April column over Europe with the seasonally varying $\mathrm{NH}_{3}$ column at three sites where ground-based monitoring of $\mathrm{NH}_{3}$ concentrations is available. The map distinguishes areas of high agricultural $\mathrm{NH}_{3}$ emissions in Brittany, E England, Netherlands and NW Germany, Po Valley and Nile Delta, whereas showing high values across Belarus and SW Russia related to forest fires during 2010. The magnitude of the $\mathrm{NH}_{3}$ columns are also a function of spatial differences in atmospheric mixing that might explain why smaller values are seen in the west compared with the east of the UK. For Stoke Ferry, where $\mathrm{NH}_{3}$ emissions are dominated by pig and poultry (see the electronic supplementary material, figure S1), both the ground-based and satellite data show spring peak $\mathrm{NH}_{3}$ values, associated with landspreading of manure. At Vredepeel, an area of intense pig and cattle farming in the Netherlands, there is less seasonality in the $\mathrm{NH}_{3}$ data, indicating a stronger contribution of controlled environment livestock housing. Lastly, at K-Puszta, a Hungarian site more distant from local sources, $\mathrm{NH}_{3}$ levels are highest in summer and lowest in winter, reflecting the integration of different environmentally dependent sources.

The satellite approach requires a strong thermal contrast, limiting its capability in winter and cloudy conditions. However, it allows the examination of spatial patterns and temporal trends with a global coverage that could never be achieved by ground-based air sampling. It thus provides an unprecedented opportunity to improve our understanding of the sources, management and climate controls on $\mathrm{NH}_{3}$, as further illustrated by seasonal $\mathrm{NH}_{3}$ patterns in different parts of the world. In the case of Po Valley, Nile Delta, California and Pakistan, there is a strong seasonal cycle in $\mathrm{NH}_{3}$, with values of $Q_{10}$ of the column totals mostly in the range $2-3$. However, not all locations show such a temperature-dependence, especially where management differences drive seasonality in $\mathrm{NH}_{3}$ emissions as seen in livestock dominated areas of Belgium and China (see the electronic supplementary material, figure S4). In order to derive the maximum value from the satellite data, these, therefore, need to be interpreted using detailed atmospheric models, as a basis to disentangle the different driving factors.

\section{Seabirds as a model system to assess climate- dependence of global ammonia emissions}

The preceding examples highlight the many factors controlling $\mathrm{NH}_{3}$ emissions, including management effects. In the case of 


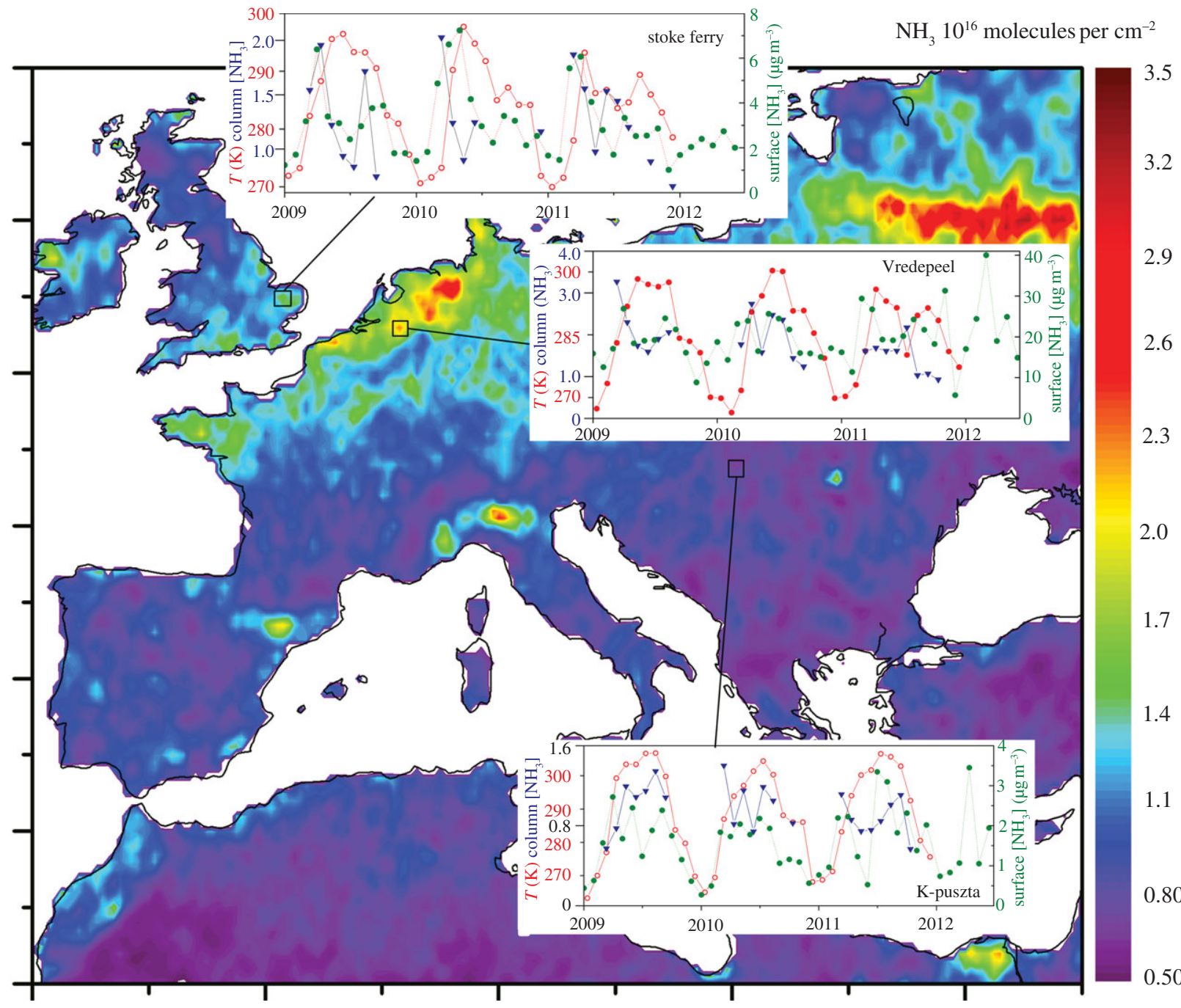

Figure 5. Satellite estimates of the $\mathrm{NH}_{3}$ column $\left(10^{6}\right.$ molecules $\left.\mathrm{cm}^{-2}\right)$ and ground temperature, showing the mean for 2009 , 2010 and 2011 (from the infrared atmospheric sounding interferometer) on the Met0p platform), as compared with ground-based measurements of atmospheric $\mathrm{NH}_{3}$ concentrations at three selected sites.

monitoring of $\mathrm{NH}_{3}$ concentrations and atmospheric columns, an even larger number of meteorological factors affect observed values. For these reasons, there is strong case to use model ecosystems to assess the climate-dependence of $\mathrm{NH}_{3}$ exchange. At present, this can uniquely be demonstrated by the case of $\mathrm{NH}_{3}$ emissions from seabird colonies, building on recent measurements and modelling [35,59].

Seabird colonies provide several advantages as a 'model system' to investigate the climate-dependence of $\mathrm{NH}_{3}$ emissions: the birds follow a well-established annual breeding cycle little affected by human management; rates of $\mathrm{N}_{\mathrm{r}}$ excretion can be directly related to dietary energetics for well-characterized populations; and they typically form locally strong $\mathrm{NH}_{3}$ sources in areas of low $\mathrm{NH}_{3}$ background. Riddick et al. [35] estimated global $\mathrm{NH}_{3}$ emission from seabird colonies at 0.3 (0.1$0.4) \mathrm{Tg} \mathrm{yr}^{-1}$. Although this is a small fraction of total emissions, it includes major point/ island sources less than $15 \mathrm{Gg} \mathrm{NH}_{3} \mathrm{yr}^{-1}$, with sites distributed globally across a wide range of climates.

Colony-scale $\mathrm{NH}_{3}$ flux measurements from seabird colonies were first reported by Blackall et al. [59] for Scottish islands, and these have been extended for contrasting climates as illustrated in figure 6. In this graph, measured $\mathrm{NH}_{3}$ emissions have been normalized by calculated $\mathrm{N}_{\mathrm{r}}$ excretion rates to show the percentage of $\mathrm{N}_{\mathrm{r}}$ that is volatilized $\left(P_{\mathrm{v}}\right)$. The measurements show a clear temperature-dependence across the globe, with $Q_{10} \sim 3$. For comparison, the dotted line is the estimate used by Blackall et al. [59] for global upscaling, whereas the solid line is the initial temperature-adjusted upscaling of Riddick et al. [35], following equation (3.3) (their scenario 2).

The importance of these measurements is emphasized by their use to verify a process-based model of $\mathrm{NH}_{3}$ emissions, the GUANO model (see the electronic supplementary material, figure S5). The model is driven by excretal inputs according to bird diet, energetics and numbers combined with a water-balance to estimate liquid-phase $\mathrm{N}_{\mathrm{r}}$ concentrations and run-off. Hydrolysis of uric acid to ammoniacal nitrogen is moistureand temperature-dependent. By combining the modelled value of $\left[\mathrm{NH}_{4}^{+}\right]$with a guano $\mathrm{pH}$ of 8.5 and ground surface temperature, equation (3.3) allows estimation of $\chi\left(z_{\mathrm{o}^{\prime}}\right)$. This is then applied in equation (3.1) to calculate hourly $\mathrm{NH}_{3}$ emission.

Application of the GUANO model shows close agreement with measurements, the hourly $\mathrm{NH}_{3}$ fluxes responding to fluctuations in surface temperature, precipitation events and wind speed. The overall measured temperature-dependence is also reproduced by the GUANO model (figure 6), including a difference between the two warmest sites, Michelmas Cay and Ascension Island. This is explained by the latter being very dry, limiting rates of uric acid hydrolysis, and hence both measured and modelled $\mathrm{NH}_{3}$ emission. 


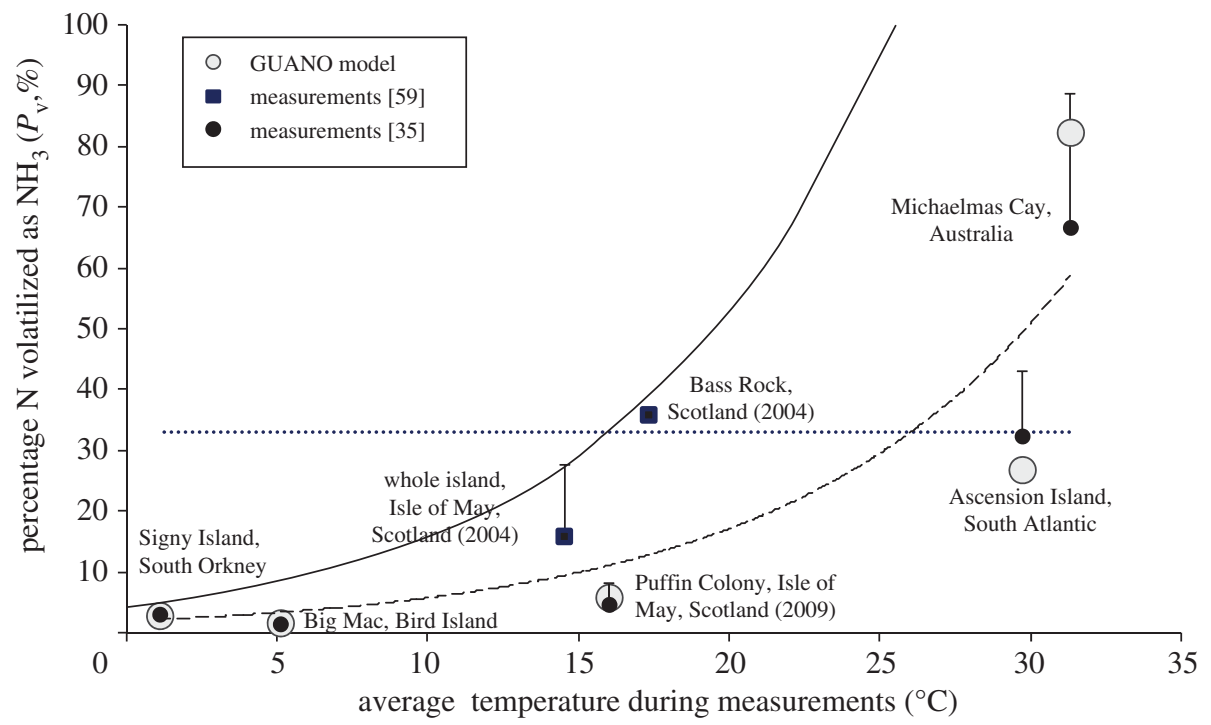

Figure 6. Measured percentage of excreted $\mathrm{N}_{\mathrm{r}}$ that is volatilized as $\mathrm{NH}_{3}\left(P_{\mathrm{v}}\right)$ as a function of mean temperature during field campaigns (dashed line: $P_{\mathrm{v}}(\%)=$ $1.9354 \mathrm{e}^{0.109} \mathrm{~T} ; \mathrm{R}^{2}=0.75$ ), as compared with estimates from the GUANO model for a global selection of seabird colonies. The dotted line shows the value used in a first bioeneregics (BE) model of Blackall et al. [59], while the solid line was applied in a temperature-adjusted bioenergetics (TABE) model, by Riddick et al. [35] using equation (3.3). The bars on the measured points apply to colonies including burrow nesting birds and indicate the estimated $P_{\mathrm{v}}$ if the colony were entirely populated by bare-rock breeders. (Online version in colour.)

Based on the verification of the GUANO model with field measurements, the global seabird and excretion datasets [35] have been applied in the model for hourly simulation of 9000 colonies for 2010-2011 (figure 7). Ground temperature turns out to be the primary driver globally, with $P_{\mathrm{v}}$ ranging from 20 to 72 per cent for sites with annual mean temperature $30^{\circ} \mathrm{C}$, wherea for sites with a mean temperature of $0^{\circ} \mathrm{C}, P_{\mathrm{v}}$ was $0-18 \%$. Variation between sites of similar temperatures is mainly attributable to differences in water availability, wind speed and nesting habitat (e.g. bare rock versus burrow breeders).

\section{Climate-dependent assessment of ammonia emissions, transport and deposition}

The examples presented for terrestrial systems including grassland, shrubland, forest and seabird colonies demonstrate the clear climatic dependence of $\mathrm{NH}_{3}$ exchange processes. Agricultural systems are more complex, and include interactions with management (including alteration of management timing and systems), $\mathrm{N}_{\mathrm{r}}$ type, animal housing and manure application method. In principle, however, many of the climatic interactions apply, and can be addressed using process-based models. The same is true for ocean-atmosphere $\mathrm{NH}_{3}$ exchange, which is bi-directional according to equation (3.1), with $\chi\left(z_{\mathrm{o}^{\prime}}\right)$ depending on variations in sea surface temperature, $\left[\mathrm{NH}_{4}^{+}\right]$concentration, water $\mathrm{pH}$ and local $\mathrm{NH}_{3}$ air concentrations. For example, future ocean acidification would tend to decrease sea surface $\mathrm{NH}_{3}$ emission. Of these factors, Johnson et al. [60] found temperature to be of overriding importance in determining ocean $\mathrm{NH}_{3}$ emissions, through its control of $\chi\left(\mathrm{z}_{\mathrm{o}^{\prime}}\right)$.

With this background, we return to the question of regional and global modelling of $\mathrm{NH}_{3}$ emission, dispersion and deposition in CTMs. Section 2 showed that there are several limitations in current $\mathrm{NH}_{3}$ emission inventories, such as information on activity data (numbers and location of animals, fertilizers, fires, etc.), average emission rates and data structure (distinction of source sectors). On a global scale, however, and given the target to assess climate change effects, by far the main limitation is that current architecture uses previously calculated emissions as input to CTMs. In reality, the same meteorology incorporated within a CTM to describe chemical transport and transformation will have a major effect on short- and long-term control of $\mathrm{NH}_{3}$ emissions, deposition and bi-directional exchange. For example, on a warm sunny day, emissions from manure, fertilizers and plants will be at their maximum, whereas cuticular deposition of $\mathrm{NH}_{3}$ will be at its minimum, with the same conditions promoting thermal convection in the atmospheric boundary layer, increasing the atmospheric transport distance.

To address the coupling of these processes requires a new paradigm for atmospheric $\mathrm{NH}_{3}$ modelling. For this purpose, the long-term goal must be to replace the use of previously determined emission inventories with a suite of spatial activity databases and models that allow emissions to be calculated online as part of the running of the CTMs. Such an approach is already widely adopted for biogenic hydrocarbon emissions from vegetation [20]. In this way, both the environmental dependence of uni-directional $\mathrm{NH}_{3}$ emissions and of bi-directional $\mathrm{NH}_{3}$ fluxes become incorporated into the overall model. In the case of the bi-directional part, online calculation is essential because of the feedback between $\chi(z)$ and the direction/magnitude of the net flux.

An outline of the proposed modelling architecture is given in figure 8, with the key new elements highlighted in green. Instead of activity data and experimentally derived relationships being used directly to provide an 'emissions inventory', with subsequent (uni-directional) dry deposition, emissions are treated in two submodels: (i) uni-directional emissions from point sources such as manure storage facilities and animal housing (where $\chi\left(z_{\mathrm{o}^{\prime}}\right) \gg \chi(z)$ ) and (ii) bi-directional fluxes from area sources (where $\chi\left(z_{\mathrm{o}^{\prime}}\right)$ less than or greater than $\chi(z)$ ), which includes emissions or dry deposition according to prevailing conditions. The same meteorological data are thus used to drive the emissions, chemistry-transport and bi-directional 


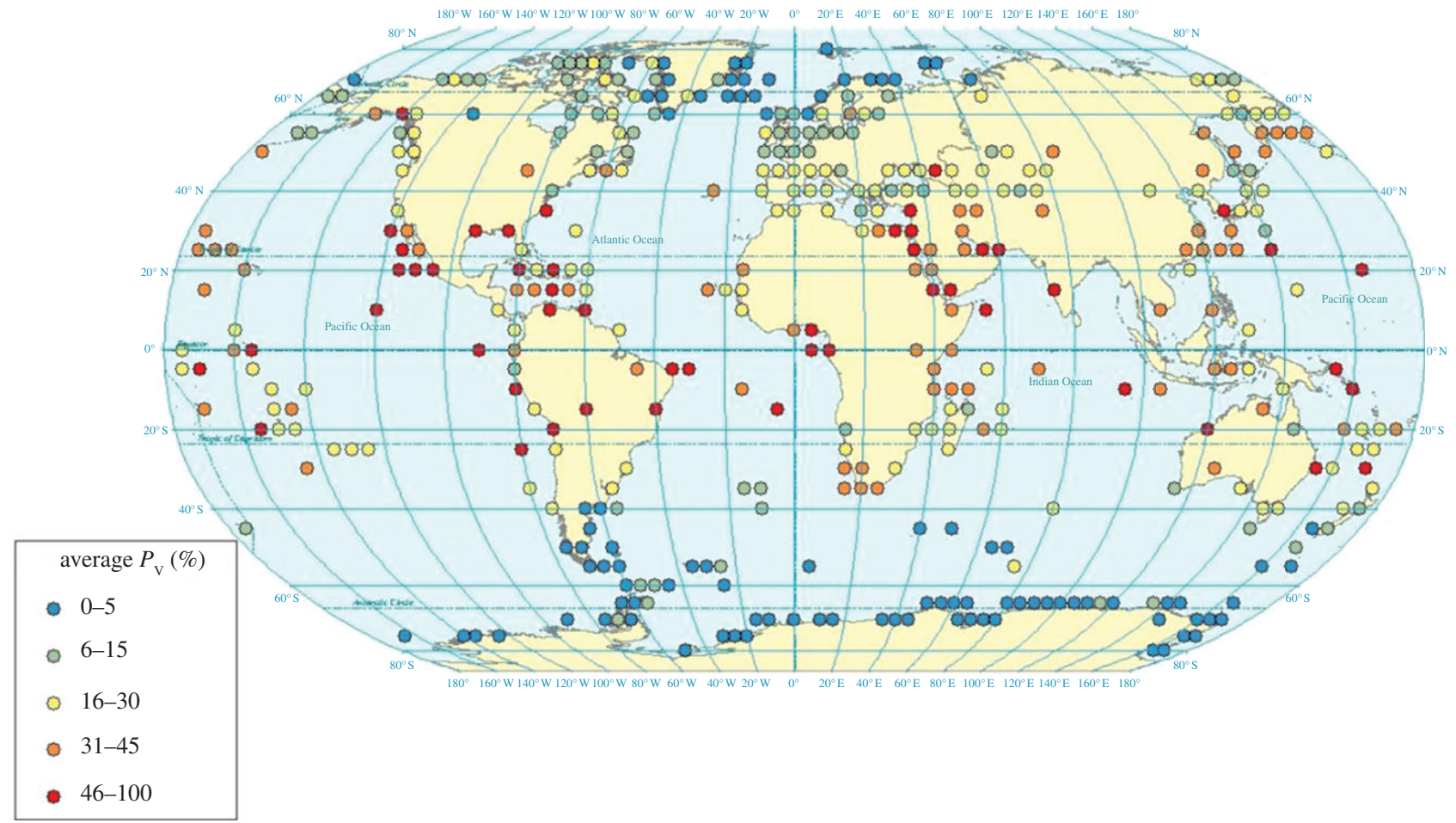

Figure 7. Global application of the GUANO model illustrating the average percentage of excreted $\mathrm{N}$ that is volatilized as $\mathrm{NH}_{3}$. Excretion calculated based on colony seabird energetics [35], combined with hourly meteorological estimates through 2010-2011.

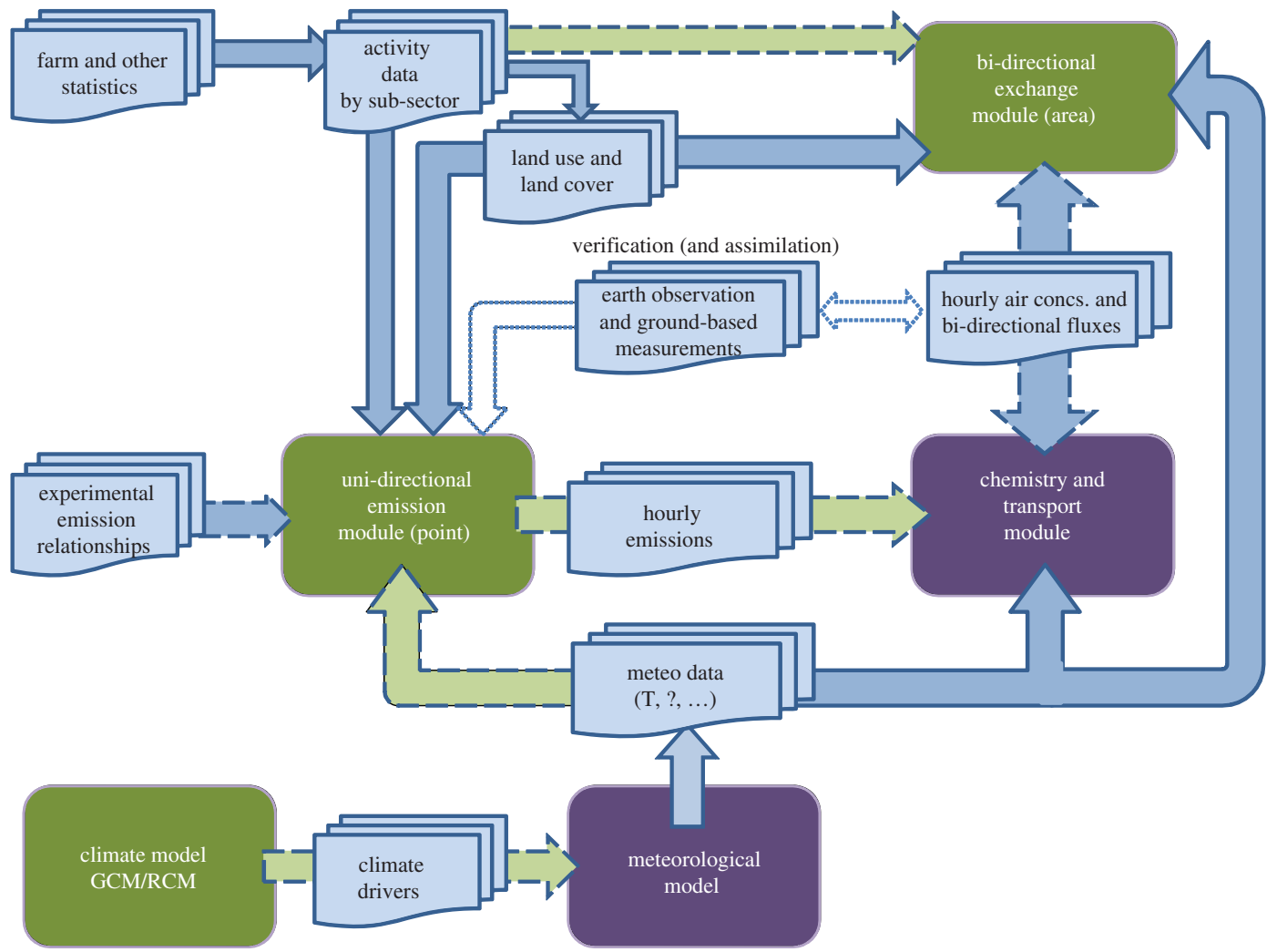

Figure 8. Proposed modelling architecture for treating the climate-dependence of ammonia fluxes in regional and global atmospheric transport and chemistry models. In this approach, static emission inventories are replaced by calculations depending on prevailing meteorology, while allowing for bi-directional exchange with area sources/sinks, giving the basis to assess climate change scenarios including the consequences of climate feedbacks through altered $\mathrm{NH}_{3}$ emissions. The effect of altered air chemistry may also be fedback into the climate model.

exchange. With this structure, climatic differences between locations are directly incorporated, whereas climate change scenarios can be directly applied.

At the present time, many of the elements for a new architecture are already available to build such a system at regional and global scales. Emission models such as those for animal houses and manure spreading [54,55] need to be linked to CTMs incorporating with bi-directional exchange parametrizations. Simple process models, following the principles used in the GUANO model should be further developed and their 
scope extended. While the most detailed dynamic model of bidirectional canopy exchange [44] has many input uncertainties, the analysis of Neirynck \& Ceulemans [53] suggests that a move from scheme 1 towards the simpler application of scheme 2 should be a feasible future target. These developments will require further information to parametrize $\Gamma$ for ecosystem components, while upscaling models must include information on canopy and ground temperature, surface wetness and relative humidity and soil $\mathrm{pH}$. While many of the necessary terms are available from meteorological models, a coupling with agricultural and ecosystem models becomes increasingly important for detailed simulation of the interactions. Challenges related to subgrid variability are addressed in the electronic supplementary material, S7.

Although not all these linkages have yet been made, significant progress in the temporal distribution of $\mathrm{NH}_{3}$ emissions according to agricultural activities has already been achieved, which can provide key input to the future developments [30,61]. For example, the US EPA Community Multiscale AirQuality model includes coupling to an agro-ecosystem model to provide dynamic- and meteorological-dependent emissions from fertilizer application, using a 2-layer bidirectional resistance model based on Nemitz et al. [15] that includes the effects of soil nitrification processes [18]. Similarly, Hamaoui-Lagel et al. [55] incorporated the VOLT'AIR model to simulate $\mathrm{NH}_{3}$ emissions from fertilizer application in a regional scale atmospheric model.

The consequences of such temporal interactions can be illustrated by the comparison of measured $\mathrm{NH}_{3}$ concentration and simulations of a Danish model [22] at a long-term monitoring site (Tange, electronic supplementary material, figure S6). In this case, the model has been used to provide the temporal disaggregation of previously calculated annual emissions. The challenge for the next stage must be to incorporate the environmental drivers in process models for all major sources to quantify the dynamics on hourly, diurnal, seasonal and annual scales, and as a foundation to estimate the effects of long-term climate change.

\section{Conclusions}

This paper has shown how ammonia emissions and deposition are fundamentally dependent on environmental conditions. While temperature has been found to be the primary environmental driver, other key factors include interactions with canopy and soil wetness and with management practices for agricultural sources. For several systems, such as emission from manure spreading, fertilizers, seabird colonies and bi-directional exchange with vegetation, process models are already available that describe the key relationships.

A new paradigm for atmospheric modelling of $\mathrm{NH}_{3}$ is proposed, where process models are incorporated with the relevant statistical data to simulate $\mathrm{NH}_{3}$ emissions as part of atmospheric models. Seabird colonies have been used here to demonstrate the global application of such a process model, verified by measurements under different climates, where the fraction of available $\mathrm{N}_{\mathrm{r}}$ volatilized as $\mathrm{NH}_{3}$ can increase by a factor of less than 20 between subpolar and tropical conditions. Although a few CTMs have incorporated bidirectional exchange, work is needed required to parametrize models for different ecosystem types and climates, and to assess the consequences of different levels of model complexity, including the coupling with ecosystem and agronomic models.

The proposed developments provide the necessary foundation to assess how climate will affect $\mathrm{NH}_{3}$ emissions, dispersion and deposition. The practical implications are that inventory activities should focus increasingly on supplying the statistical activity data needed to drive the models (rather than only publishing static $\mathrm{NH}_{3}$ emission estimates) and that national $\mathrm{NH}_{3}$ emissions for any year can only be calculated with confidence once the meteorological data are available.

Based on the available measurements and models, it is possible to indicate empirically the scale of the climate risk for $\mathrm{NH}_{3}$. Marine $\mathrm{NH}_{3}$ emissions are expected to follow the thermodynamic response directly equation (3.3), whereas a reduced $Q_{10}$ of 2 (1.5-3) may be applied for terrestrial volatilization sources. (For procedures, see the electronic supplementary material, section 8, figures S7, S8 and equations for use in scenario models). Applying these responses to the 2008 global estimates of 65 (46-85) $\mathrm{Tg} \mathrm{N} \mathrm{yr}^{-1}$ for a $5^{\circ} \mathrm{C}$ global temperature increase to 2100 would increase $\mathrm{NH}_{3}$ emissions by approximately 42 per cent $(28-67 \%)$ to $93(64-125) \mathrm{Tg}$. If this is combined with a further 56 per cent $(44-67 \%)$ increase in anthropogenic source activities [62], total $\mathrm{NH}_{3}$ emissions would reach 132 (89-179) Tg by 2100. Considering these major anticipated increases, the limited progress in $\mathrm{NH}_{3}$ mitigation efforts to date, and the slow nature of behavioural change, stepping up efforts to control $\mathrm{NH}_{3}$ emission must be a key priority for future policy development.

Full acknowledgements, including from the European Commission, European Space Agency, US EPA, other national funding sources and individuals are listed in the electronic supplementary material. This paper is a contribution to the International Nitrogen Initiative (INI) and to the UNECE Task Force on Reactive Nitrogen (UNECE) [63].

\section{References}

1. Erisman JW, Sutton MA, Galloway JN, Klimont Z, Winiwarter W. 2008 How a century of ammonia synthesis changed the world. Nat. Geosci. 1, 636639. (doi:10.1038/nge0325)

2. Sutton MA, Erisman JW, Dentener F, Möller D. 2008 Ammonia in the environment: from ancient times to the present. Environ. Pollut. 156, 583-604. (doi:10.1016/j.envpol.2008.03.013)

3. CEIP. 2012 Overview of submissions under CLRTAP: 2012. Vienna, Austria: Centre for Emissions
Inventories and Projections, Umweltbundesamt (www.ceip.at/overview-of-submissions-underclrtap/2012-submissions/)

4. UNECE. 2012 Draft decision on amending the text of and annexes II to IX to the Gothenburg protocol to abate acidification, eutrophication and ground-level ozone and addition of new annexes $X$ and XI. Geneva, Switzerland: Executive Body for the Convention on Long-range Transboundary Air Pollution.
5. Pinder RW, Gilliland AB, Dennis RL. 2008 Environmental impact of atmospheric $\mathrm{NH}_{3}$ emissions under present and future conditions in the eastern United States. Geophys. Res. Letts. 35, L12808. (doi:10.1029/2008GL033732)

6. Sutton MA. 2011 Summary for policy makers. In The European nitrogen assessment (eds MA Sutton, CM Howard, JW Erisman, G Billen, A Bleeker, P Grennfelt, $H$ van Grinsven, B Grizzetti), pp. xxivxxxiv. Cambridge, UK: Cambridge University Press. 
7. Sutton MA, Oenema 0, Erisman JW, Leip A, van Grinsven H, Winiwarter W. 2011 Too much of a good thing. Nature 472, 159-161. (doi:10.1038/ 472159a)

8. Denmead OT, Freney JR, Simpson JR. 1976 A closed ammonia cycle within a plant canopy. Soil Sci. Biochem. 8, 161-164. (doi:10.1016/00380717(76)90083-3)

9. Farquhar GD, Firth PM, Wetselaar R, Wier B. 1980 On the gaseous exchange of ammonia between leaves and the environment: determination of the ammonia compensation point. Plant Physiol. 66, 710-714. (doi:10.1104/pp.66.4.710)

10. Sutton MA, Schjorring JK, Wyers GP. 1995 Plant atmosphere exchange of ammonia. Phil.

Trans. R. Soc. A 351, 261-276. (doi:10.1098/rsta. 1995.0033)

11. Sutton MA. 2009 Dynamics of ammonia exchange with cut grassland: synthesis of results and conclusions of the GRAMINAE integrated experiment. Biogeosciences 6, 2907-2934. (doi:10. 5194/bg-6-2907-2009)

12. Sutton MA, Reis S, Baker SMH (eds). 2009 Atmospheric ammonia: detecting emission changes and environmental impacts, p. 464. Berlin, Germany: Springer.

13. Schjoerring JK, Husted S, Mattsson M. 1998 Physiological parameters controlling plantatmosophere ammonia exchange. Atmos. Environ. 32, 491-498. (doi:10.1016/S1352-2310(97)00006-X)

14. Hertel 0 et al. 2011 Nitrogen -rocesses in the atmosphere. In The European nitrogen assessment (eds MA Sutton, CM Howard, JW Erisman, G Billen, A Bleeker, P Grennfelt, H van Grinsven, B Grizzetti), Ch. 9, pp. 177-207. Cambridge, UK: Cambridge University Press.

15. Nemitz E, Milford C, Sutton MA. 2001 A two-layer canopy compensation point model for describing bidirectional biosphere/atmosphere exchange of ammonia. Q. J. Roy. Meteor. Soc. 127, 815-833. (doi:10.1256/smsqj.57305)

16. Dentener FJ, Crutzen PJ. 1994 A three-dimensional model of the global ammonia cycle. J. Atmos. Chem. 19, 331-369. (doi:10.1007/BF00694492)

17. Wichink Kruit RJ, Schaap M, Sauter FJ, Van Zanten MC, van Pul WAJ. 2012 Modeling the distribution of ammonia across Europe including bi-directional surface-atmosphere exchange. Biogeosci. Discuss. 9, 4877-4918. (doi:10.5194/bgd-9-4877-2012)

18. Bash J0, Cooter EJ, Dennis RL, Walker JT, Pleim JE. 2012 Evaluation of a regional air-quality model with bi-directional $\mathrm{NH}_{3}$ exchange coupled to an agro-ecosystem model. Biogeosci. Discuss. 9 , 11 375-11 401. (doi:10.5194/bgd-9-11375-2012)

19. Cape JN, van der Eerden LJ, Sheppard LJ, Leith ID, Sutton MA. 2009 Evidence for changing the critical level for ammonia. Environ. Pollut. 157, 1033-1037. (doi:10.1016/ j.envpol.2008.09.049)

20. Simpson D et al. 2011 Atmospheric transport and deposition of reactive nitrogen in Europe. In The European nitrogen assessment (eds MA Sutton, CM Howard, JW Erisman, G Billen, A Bleeker,
P Grennfelt, H van Grinsven, B Grizzetti), ch. 14, pp. 298-316. Cambridge, UK: Cambridge University Press.

21. Velthof VGL, van Bruggen C, Groenestein CM, de Haan BJ, Hoogeveen MW, Huijsmans JFM. 2012 A model for inventory of ammonia emissions from agriculture in the Netherlands. Atmos. Environ. 46, 248-255. (doi:10.1016/j.atmosenv.2011.09.075)

22. Geels ( et al. 2012 A coupled model system (DAMOS) improves the accuracy of simulated atmospheric ammonia levels over Denmark. Biogeosci. Discuss. 9, 1587-1634. (doi:10.5194/ bgd-9-1587-2012)

23. Dragosits U, Sutton MA, Place CJ, Bayley A. 1998 Modelling the spatial distribution of ammonia emissions in the UK. Environ. Pollut. 102, 195-203. (doi:10.1016/50269-7491(98)80033-X)

24. Webb J, Misselbrook TH. 2004 A mass-flow model of ammonia emissions from UK livestock production. Atmos. Environ. 38, 2163-2176. (doi:10.1016/j. atmosenv.2004.01.023)

25. de Vries W, Leip A, Reinds GJ, Kros J, Lesschen JP, Bouwman AF. 2011 Comparison of land nitrogen budgets for European agriculture by various modeling approaches. Environ. Pollut. 159, 3254-3268. (doi:10.1016/j.envpol.2011.03.038)

26. Bleeker $A$ et al. 2009 Linking ammonia emission trends to measured concentrations and deposition of reduced nitrogen at different scales. In Atmospheric ammonia: detecting emission changes and environmental impacts (eds MA Sutton, $\mathrm{S}$ Reis, SMH Baker), pp. 123-180. Berlin, Germany: Springer.

27. Misselbrook TH, Sutton MA, Scholefield D. 2004 A simple process-based model for estimating ammonia emissions from agricultural land after fertilizer applications. Soil Use Man. 20, 365-372. (doi:10.1079/SUM2004280)

28. Gross A, Boyd CE, Wood CW. 1999 Ammonia volatilization from freshwater fish ponds. J. Environ. Qual. 28, 793-797. (doi:10.2134/jeq1999. 00472425002800030009x)

29. Sutton MA, Dragosits U, Tang YS, Fowler D. 2000 Ammonia emissions from non-agricultural sources in the UK. Atmos. Environ. 34, 855-869. (doi:10 1016/51352-2310(99)00362-3)

30. Skjøth CA et al. 2011 Spatial and temporal variations in ammonia emissions: a freely accessible model code for Europe. Atmos. Chem. Phys. 11, 5221-5236. (doi:10.5194/acp-11-5221-2011)

31. Bouwman AF, Lee DS, Asman WAH, Dentener FJ, Van der Hoek KW, Olivier JGJ. 1997 A global highresolution emission inventory for ammonia. Glob. Biogeochem. Cycles 11, 561-587. (doi:10.1029/ 97GB02266)

32. Van Aardenne JA, Dentener FJ, Olivier JGJ, Klein Goldewijk CGM, Lelieveld J. $2001 \mathrm{~A} 1^{\circ} \times 1^{\circ}$ resolution data set of historical anthropogenic trace gas emissions for the period 1890-1990. Glob. Biogeochem. Cycles 15, 909-928. (doi:10.1029/ 2000GB001265)

33. Beusen AHW, Bouwman AF, Heuberger PSC, van Drecht G, an Der Hoek KW. 2008 Bottom-up uncertainty estimates of global ammonia emissions from global agricultural production systems. Atmos. Environ. 42, 6067-6077. (doi:10.1016/j.atmosenv. 2008.03.044)

34. JRC/PBL. 2011 Emission database for global atmospheric research, EDGAR v. 4.2. See http:// edgar.jrc.ec.europa.eu/.

35. Riddick SN, Dragosits U, Blackall TD, Daunt F, Wanless S, Sutton MA. 2012 The global distribution of ammonia emissions from seabird colonies. Atmos. Environ. 55, 319-327. (doi:10.1016/j. atmosenv.2012.02.052)

36. Andres RJ, Kasgnoc AD. 1998 A time-averaged inventory of subaerial volcanic sulfur emissions. J. Geophys. Res. 103, 25 251-25 261. (doi:10.1029/ 98JD02091)

37. Clarisse L, Clerbaux C, Dentener F, Hurtmans D, Coheur PF. 2009 Global ammonia distribution derived from infrared satellite observations. Nat. Geosci. 2, 479-483. (doi:10.1038/nge0551)

38. Bouwman AF, Boumans LJM, Batjes NH. 2002 Estimation of global $\mathrm{NH}_{3}$ volatilization loss from synthetic fertilizers and animal manure applied to arable lands and grasslands. Glob. Biogeochem. Cycles 16, 1024. (doi:10.1029/2000GB001389)

39. Flechard CR, Fowler D. 1998 Atmospheric ammonia at a moorland site. I. The meteorological control of ambient ammonia concentrations and the influence of local sources. Q. J. R. Meteor. Soc. 124, 733-757. (doi:10.1002/qj.49712454705)

40. Fowler D et al. 2009 Atmospheric composition change: ecosystems: atmosphere interactions. Atmos. Environ. 43, 5193-5267. (doi:10.1016/j. atmosenv.2009.07.068)

41. Nemitz E, Sutton MA. 2004 Gas-particle interactions above a Dutch heathland. III. Modelling the influence of the $\mathrm{NH}_{3}-\mathrm{HNO}_{3}-\mathrm{NH}_{4} \mathrm{NO}_{3}$ equilibrium on size-segregated particle fluxes. Atmos. Chem. Phys. 4, 1025-1045. (doi:10.5194/acp-4-10252004)

42. Loubet B et al. 2009 Ammonia deposition near hot spots: processes, models and monitoring methods. In Atmospheric ammonia: detecting emission changes and environmental impacts (eds MA Sutton, S Reis, SMH Baker), pp. 205-267. Berlin, Germany: Springer.

43. Sutton MA, Burkhardt JK, Guerin D, Nemitz E, Fowler D. 1998 Development of resistance models to describe measurements of bi-directional ammonia surface atmosphere exchange. Atmos. Environ. 32, 473-480. (doi:10.1016/S13522310(97)00164-7)

44. Flechard C, Fowler D, Sutton MA, Cape JN. 1999 A dynamic chemical model of bi-directional ammonia exchange between semi-natural vegetation and the atmosphere. Q. J. R. Meteorol. Soc. 125, 2611-2641. (doi:10.1002/qj.49712555914)

45. Mattsson M et al. 2009 Temporal variability in bioassays of the stomatal ammonia compensation point in relation to plant and soil nitrogen parameters in intensively managed grassland. Biogeosciences 6, 171-179. (doi:10.5194/bg6-171-2009) 
46. Massad R-S, Nemitz E, Sutton MA. 2010 Review and parameterisation of bi-directional ammonia exchange between vegetation and the atmosphere. Atmos. Chem. Phys. 10, $10359-10$ 386. (doi:10. 5194/acp-10-10359-2010)

47. Wichink Kruit RJ, van Pul WAJ, Sauter FJ, van den Broek M, Nemitz E, Sutton MA, Krol M, Holtslag AAM. 2010 Modeling the surfaceatmosphere exchange of ammonia. Atmos. Environ. 44, 945-957. (doi:10.1016/j.atmosenv. 2009.11.049)

48. Riedo M, Milford C, Schmid M, Sutton MA. 2002 Coupling soil-plant-atmosphere exchange of ammonia with ecosystem functioning in grasslands. Ecol. Model. 158, 83 -110. (doi:10.1016/503043800(02)00169-2)

49. Wu YH, Walker J, Schwede D, Peters-Lidard C, Dennis $R$, Robarge W. 2009 A new model of bidirectional ammonia exchange between the atmosphere and biosphere: ammonia stomatal compensation point. Agr. Forest Meteorol. 149, 263-280. (doi:10.1016/j.agrformet.2008.08.012)

50. Massad R-S, Tuzet A, Loubet B, Perrier A, Cellier P. 2010 Model of stomatal ammonia compensation point (STAMP) in relation to the plant nitrogen and carbon metabolisms and environmental conditions. Ecol. Model. 221, 479-494. (doi:10.1016/j.ecol model.2009.10.029)

51. Zhang L, Wright PL, Asman WAH. 2010 Bidirectional airsurface exchange of atmospheric ammonia: a review of measurements and a development of a big-leaf model for applications in regional-scale air-quality models. J. Geophys. Res. 115, D20310. (doi:10.1029/2009JD013589)

52. Burkhardt J et al. 2009 Modelling the dynamic chemical interactions of atmospheric ammonia with leaf surface wetness in a managed grassland canopy. Biogeosciences 6, 67-84. (doi:10.5194/bg6-67-2009)

53. Neirynck J, Ceulemans R. 2008 Bidirectional ammonia exchange above a mixed coniferous forest. Environ. Pollut. 154, 424-438. (doi:10.1016/j. envpol.2007.11.030)

54. Génermont S, Cellier P. 1997 A mechanistic model for estimating ammonia volatilization from slurry applied to bare soil. Agr. Forest Meteorol. 88, 145-167. (doi:10.1016/50168-1923(97)00044-0)

55. Hamaoui-Laguel L, Meleux F, Beekmann M, Bessagnet $B$, Génermont $S$, Cellier $P$, Létinois $L$. 2012 Improving ammonia emissions in air quality modelling for France. Atmos. Environ. (doi:10.1016/ j.atmosenv.2012.08.002)

56. Søgaard HT, Sommer SG, Hutchings NJ, Huijsmans JFM, Bussink DW, Nicholson F. 2002 Ammonia volatilization from field-applied animal slurry-the ALFAM model. Atmos. Environ. 36, 3309-3319. (doi:10.1016/S1352-2310(02)00300-X)

57. Nemitz E, Sutton MA, Wyers GP, Jongejan PAC. 2004 Gas-particle interactions above a Dutch heathland. I. Surface exchange fluxes of $\mathrm{NH}_{3}, \mathrm{SO}_{2}, \mathrm{HNO}_{3}$ and
HCl. Atmos. Chem. Phys. 4, 989-1005. (doi:10. 5194/acp-4-989-2004)

58. Hellsten S, Dragosits U, Place C, Misselbrook TH, Tang YS, Sutton MA. 2007 Modelling seasonal dynamics from temporal variation in agricultural practices in the UK ammonia emission inventory. Water Air Soil Pollut Focus 7, 3-13. (doi:10.1007/ s11267-006-9087-5)

59. Blackall TD et al. 2007 Ammonia emissions from seabird colonies. Geophys. Res. Lett. 34, L10801. (doi:10.1029/2006GL028928)

60. Johnson MT et al. 2008 Field observations of the ocean-atmosphere exchange of ammonia: Fundamental importance of temperature as revealed by a comparison of high and low latitudes. Glob. Biogeochem. Cycles 22, GB1019. (doi:10.1029/ 2007GB003039)

61. Gilliland AB, Appel KW, Pinder RW, Dennis RL. 2006 Seasonal $\mathrm{NH}_{3}$ emissions for the continental united states: Inverse model estimation and evaluation. Atmos. Environ. 40, 4986-4998. (doi:10.1016/j. atmonsenv.2005.12.066)

62. David F, John P, John R, Mark S 2013 The global nitrogen cycle in the 21st century. Phil. Trans. R. Soc. B 368, 20130165. (doi:10.1098/rstb. 2013.0165)

63. Skjoth CA, Geels C. 2012 The effect of climate and climate change on ammonia emissions in Europe. Atmos. Chem. Phys. Discuss. (doi:10.5194/acpd-121-2012) 


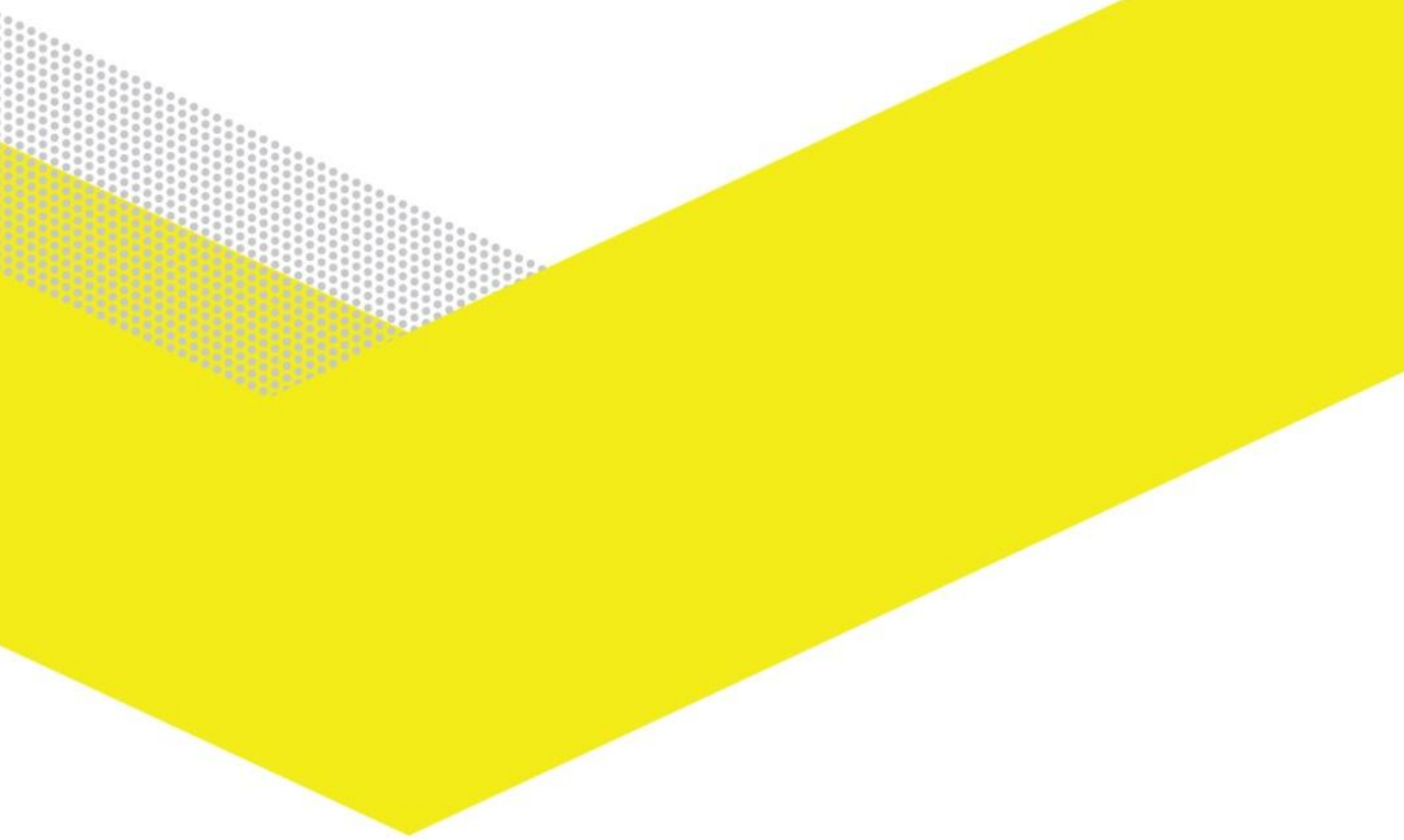

ECN

Westerduinweg $3 \quad$ Postbus 1

1755 LE Petten 1755 LG Petten

T 0885154949

F 0885158338

info@ecn.nl

www.ecn.nl 